Proc Soc Antiq Scot, 119 (1989), 59-61

\title{
The cultivation remains beneath the North Mains, Strathallan barrow
}

\author{
Gordon J Barclay*
}

\begin{abstract}
Cultivation ridges found beneath a barrow of the early second millennium bc are described.
\end{abstract}

When the massive burial mound at North Mains, Strathallan, Perthshire was excavated (Barclay 1983) clear traces of cultivation ridges were found beneath it. They were described in the North Mains report (ibid, 191):

'The ridges were a maximum of $0.15 \mathrm{~m}$ high and measured 1.8 to $2 \mathrm{~m}$ from crest to crest'.

A plan of the ridging was not published with the excavation report. A camera failure on site had resulted in there being only a colour slide of the features. In the process of having a monochrome plate of this slide prepared, it was mislaid within the HBM photographic library until after the report had gone to press.

In 1979 there were few parallels for the features below the mound; only on Arran (Barber 1982, 362, pl 363) and at Callanish, Lewis (Ashmore, pers comm) had similar features been found in Scotland. Ridging, c 1.5 m crest to crest, had also been found under structures of the Roman fort at Rudchester in Northumberland (Gillam et al 1973). Since then the discovery of cord rig in the Borders (Halliday 1986) has shown that prehistoric cultivation remains of this kind are probably far more widespread than had been thought. Halliday notes that the ridges in the Borders are generally $1.3 \mathrm{~m}$ broad, in contrast to the broader ridging below the barrow. The North Mains barrow was built in the early second millennium bc, providing a terminus ante quem for the ridging.

As the debate on the date and function of narrow ridges gains pace it was felt that the hitherto unpublished information from North Mains should be made available.

Illustration 1 is the plan of those features on the old land surface which could be recorded; other, slighter ridging could be seen but could not be drawn. Site north lies at the top of the page; the plan can easily be related to the plans in the site report, by reference to the position of the baulks. It should be noted that the more steeply sided furrows in the south-eastern quadrant of the mound (at the bottom right) were very much narrower than those in the north.

Illustration 2 is a monochrome print, taken from a colour slide, of the ridging seen on the old land surface of the north-eastern quadrant (the top left of illus 1) viewed from the west.

It is to be hoped that the work on Scottish narrow ridging, on Arran, at Callanish, at Hut Knowe, and in the Borders generally, will soon be published.

*Historic Buildings \& Monuments, Scottish Development Department, 20 Brandon Street, Edinburgh 


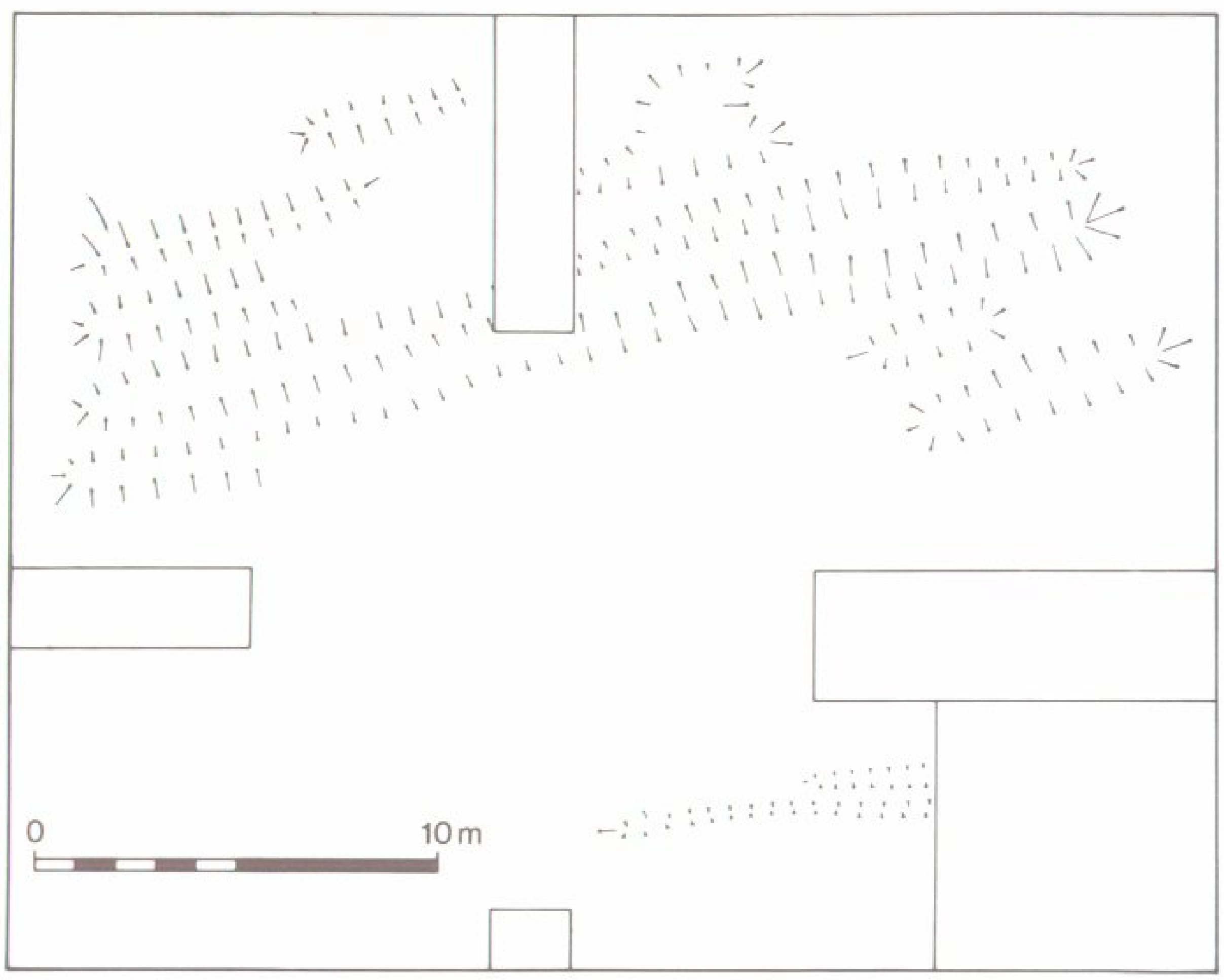

ILLus 1 Plan of recorded features on old land surface, North Mains, Strathallan

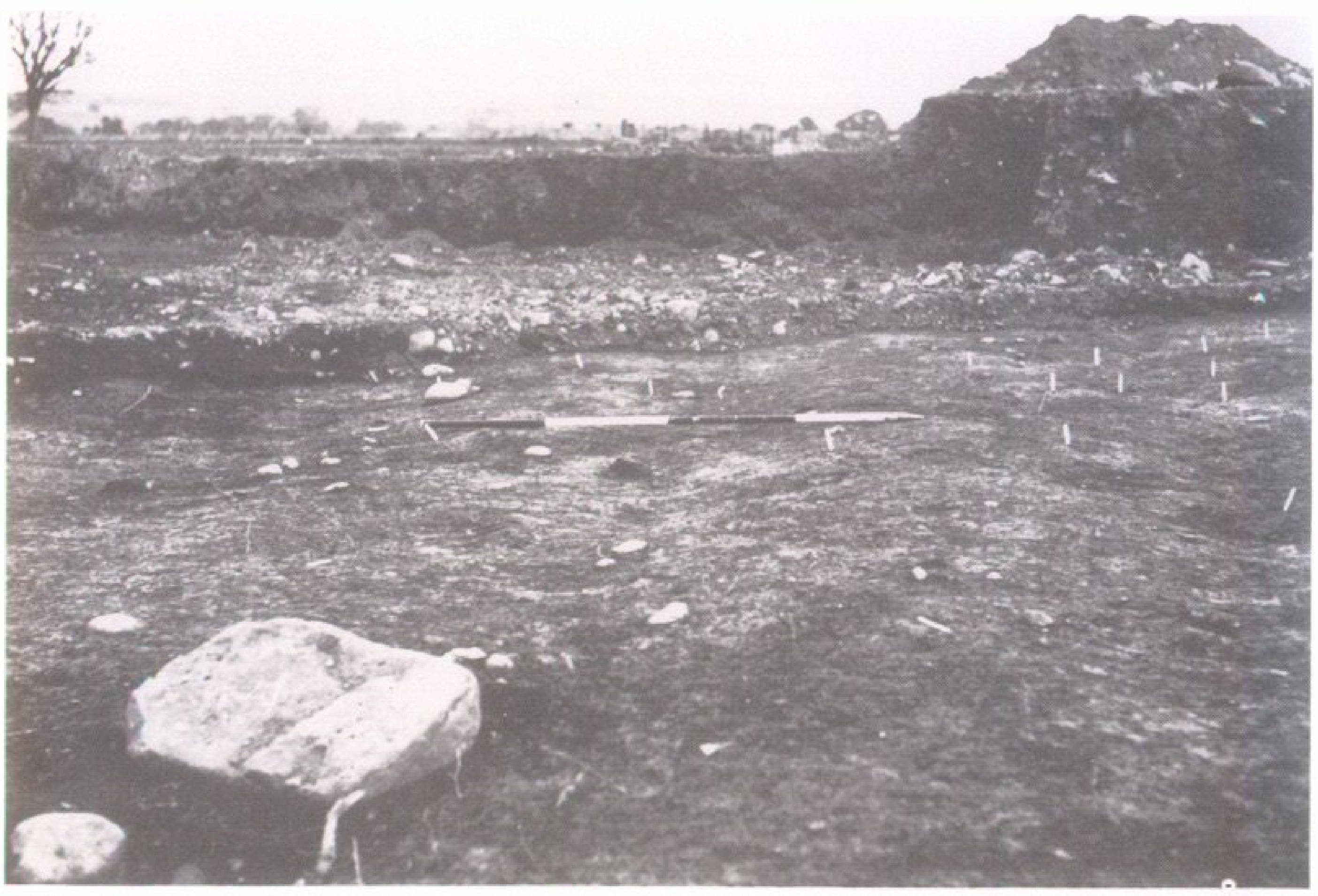

ILlus 2 Ridging on old land surface of north-eastern quadrant, North Mains, Strathallan. Viewed from west 


\section{REFERENCES}

Barber, J 1982 'Arran', Curr Archaeol, 83 (1982), 358-63.

Barclay, G J 1983 'Sites of the third millennium bc to the first millennium ad at North Mains, Strathallan, Perthshire', Proc Soc Antiq Scot, 113 (1983), 122-281.

Gillam, J P, Harrison, R M \& Newman, T G 1973 'Interim report on excavations at the Roman fort at Rudchester', Archaeol Aeliana, 5 ser, 1 (1973), 81-5.

Halliday, S 1986 'Cord rig and early cultivation in the Borders', Proc Soc Antiq Scot, 116 (1986), 584-5.

This paper is published with the aid of a grant from the Historic Buildings and Monuments Directorate (SDD) 